\title{
Effect of surface properties on the fatigue life of manufactured parts: experimental analysis and multi-axial criteria.
}

\author{
Habib Sidhom ${ }^{1}$, Naoufel ben Moussa ${ }^{1}$, Brahim ben Fathallah ${ }^{1}$, \\ Naziha Sidhom ${ }^{1}$, and Chedly Braham ${ }^{2}$ \\ 1- Mechanical, Materials and Processes Laboratory (LR99ES05), ENSIT, 5, Avenue Taha Hussein \\ 1008, University of Tunis, Tunisia \\ 2- Laboratoire de Procédés et Ingénierie en Mécanique et Matériaux (PIMM-UMR CNRS 8006), \\ ENSAM, 151, Boulevard de l'Hôpital, 75013 Paris, France
}

\begin{abstract}
The effects of machined and treated surface characteristics on the fatigue strength were analyzed on the basis of experimental results related to AISI D2 ground surface and AA 5083-H111 hammered surface. The fatigue strength improvement resulting from controlled grinding and mechanical surface treatment was discussed on the basis of the beneficial effect of the work hardening and the stabilized residual stress. A numerical procedure using F.E.M for calculating residual stress and work hardening evolution under cyclic loading has been developed. The validation of the numerical procedure was carried out by comparing the calculated residual stress profiles to those resulted from XRD measurements. The multi-axial criterion accounting for the work hardening and the residual stress was used to predict the fatigue life of notched samples.
\end{abstract}

\section{Introduction}

It is well established that residual stress and work hardening, generated by machining and surface treatment processes, influence the fatigue life of mechanical parts [1-3]. That is why they are often considered in fatigue strength predictive models using multi-axial fatigue criteria [3] and fatigue life assessment by local strain-life approaches $[4,5]$. Experimental and modeling results confirm the detrimental effect of tensile residual stress which is considered to promote fatigue crack nucleation and to accelerate their propagation [6]. In contrary, it has been demonstrated that the compressive residual stress, generated by controlled machining processes and surface treatments, improves the fatigue strength by delaying the crack nucleation and by reducing the crack propagation rate [2, 7 , 8]. However, most of published data related to fatigue crack nucleation and growth involving residual stress were discussed on the basis of their initial distribution [9-11]. Moreover, the majority of fatigue predictive methods take into account the initial measured residual stress values and neglect their evolution under cyclic loading. This assumption is controversial by published data related to stabilized residual stress profiles showing relaxation and redistribution phenomena $[2,8$, $12,13]$. Moreover, it has been reported that the most fraction of residual stress relaxation is monotonic, since it occurs at first cycles. Relaxation could progress under cyclic loading if the plastic misfit itself continues to change until stability [13-15].

Since the stabilized residual stress state is an important parameter for fatigue life prediction, it is of paramount importance to determine, in this study, the parameters that govern their evolution during cyclic loading. These parameters will be taken into account by the developed numerical procedure to calculate stabilized residual stresses and therefore fatigue life time. Analysis of the residual stress cyclic stability is based on the experimental results of surface characterization and fatigue tests conducted on AISI D2 ground surface and AA 5083-H111 machined and wire brush hammered surfaces.

\section{Materials, tests and methods}

- Materials

Two materials were investigated: a hard AISI D2 steel (EN X160CrMoV12) and a ductile aluminum alloy (AA 5083-H111). Their chemical compositions and mechanical properties are reported in tables 1 and 2 , respectively. 
Table 1. Chemical compositions (\% weight)

\begin{tabular}{cccccccccccc}
\hline AISI D2 steel & $\mathrm{C}$ & $\mathrm{Si}$ & $\mathrm{Mn}$ & $\mathrm{P}$ & $\mathrm{S}$ & $\mathrm{Cr}$ & $\mathrm{Ni}$ & $\mathrm{Mo}$ & $\mathrm{Cu}$ & $\mathrm{V}$ & $\mathrm{Fe}$ \\
& 1.59 & 0.38 & 0.35 & 0.024 & 0.015 & 11.68 & 0.36 & 0.67 & 0.03 & 0.39 & balance \\
\hline AA 5083-H111 & $\mathrm{Si}$ & $\mathrm{Fe}$ & $\mathrm{Cu}$ & $\mathrm{Mn}$ & $\mathrm{Mg}$ & $\mathrm{Cr}$ & $\mathrm{Ni}$ & $\mathrm{Zn}$ & $\mathrm{Ti}$ & $\mathrm{Pb}$ & $\mathrm{Al}$ \\
& 0.15 & 0.28 & 0.02 & 0.761 & 4.24 & 0.133 & 0.002 & 0.01 & 0.014 & 0.0001 & balance \\
\hline
\end{tabular}

Table 2. Mechanical properties

\begin{tabular}{llllll}
\hline \multirow{2}{*}{ AISI D2 } & $\mathrm{Rp}_{0.2}(\mathrm{MPa})$ & $\mathrm{Rm}(\mathrm{MPa})$ & $\mathrm{A}(\%)$ & $\mathrm{E}(\mathrm{GPa})$ & $\mathrm{Hv}_{0.1}$ \\
AA 5083-H111 & 1530 & 1850 & 3.6 & 207 & 800 \\
& 140 & 312 & 24 & 72 & 82 \\
\hline
\end{tabular}

- Surface mode preparation

The hard material AISI D2 steel was ground with two wheel types $\mathrm{Al}_{2} \mathrm{O}_{3}(95$ A $46 \mathrm{H} \mathrm{V} \mathrm{S}$ ) and sol gel (3 SG $46 \mathrm{H} \mathrm{V} \mathrm{S})$ at wheel speed $\left(\mathrm{V}_{\mathrm{s}}=22 \mathrm{~m} / \mathrm{s}\right)$, work speed $\left(\mathrm{V}_{\mathrm{w}}=0.15 \mathrm{~m} / \mathrm{s}\right)$ and depth of cut (ap= $3 \mathrm{~mm}$ ). The ductile material AA 5083-H111 was milled and wire brush hammered (Almen intensity $=\mathrm{F} 5.9 \mathrm{~N})$.

- Tests and methods

The processes induced work hardening was investigated before and after fatigue tests, by microhardness measurements using a microhardness tester set type Shimadzu. The near surface residual stress distributions were evaluated before and after loading using the X-ray diffraction method (XRD) performed on the Proto XRD device, according to the conditions listed in Table 3. The bending fatigue tests at imposed stress and stress ratio $R_{0.1}$ were carried out on notched specimens (Fig. 1).

A 2D finite element model is developed for simulating the bending tests using ABAQUS program. The finite element model integrates meshing, loading conditions, cyclic material behavior and calculation steps. The experimental profiles of residual stress and work hardening are taken into account in the finite element model (FEM) as an initial condition using subroutines SIGINI and HARDINI, respectively. The behavior of the aluminum alloy AA5083-H111 under cyclic loading is described in this work by the isotropic and nonlinear kinematic hardening model proposed by Chaboche [16]. The material coefficients k, Q, b, C and $\gamma$ are identified from experimental stressstrain hysteresis loops corresponding to different imposed strain range and summarized in Table 4.

\begin{tabular}{ll}
\multicolumn{2}{c}{ Table 3 X-ray diffraction parameters } \\
\hline Radiation & $\mathrm{Cr} \mathrm{K \alpha}$ radiation $(\lambda=0.229 \mathrm{~nm})$ \\
Voltage & $20 \mathrm{kV}$ \\
Current & $5 \mathrm{~mA}$ \\
X-ray diffraction planes & $\{311\}, 2 \theta=139.5^{\circ}$ for AA $5083-\mathrm{H} 111$ \\
& $\{211\}, 2 \theta=156^{\circ}$ for AISI D2 \\
Beam diameter & $2 \mathrm{~mm}$ \\
Angles $\phi$ & $0^{\circ}$ and $90^{\circ}(2$ directions $)$ \\
$\psi$ oscillation & $\pm 3^{\circ}$ \\
Tilt angles $\psi$ & 17 angles from $-39.23^{\circ}$ \\
\hline
\end{tabular}

Table 4 Cyclic behavior law coefficients of AA 5083-H111

\begin{tabular}{ccccccc}
\hline $\mathrm{E}(\mathrm{GPa})$ & $v$ & $\mathrm{~K}(\mathrm{MPa})$ & $\mathrm{Q}(\mathrm{MPa})$ & $\mathrm{b}$ & $\mathrm{C}(\mathrm{MPa})$ & $\gamma$ \\
70 & 0.33 & 100 & 103 & 6.44 & 30000 & 350 \\
\hline
\end{tabular}




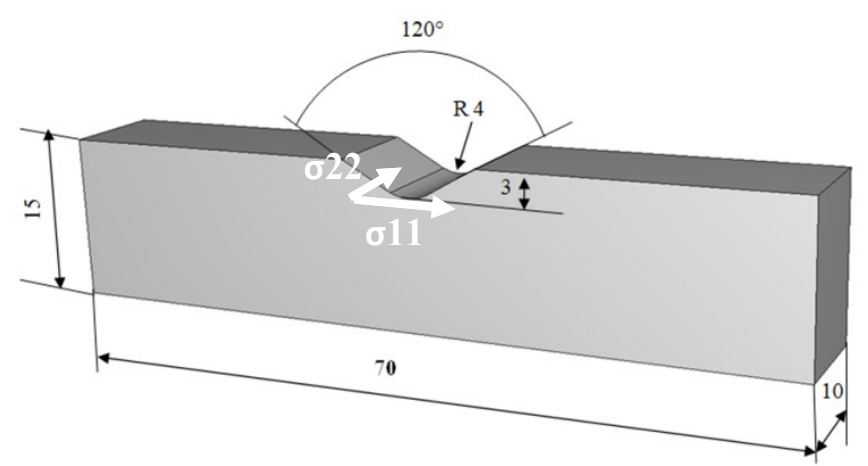

Fig. 1 Notched fatigue specimen

\section{Cyclic stability of residual stress in AISI D2 ground surface and their consequences on fatigue strength}

Grinding generates work hardening and residual stress distributions depending on the grinding wheel type. Initial work hardening profile, showed in Fig. 2, indicates a thin softener layers attributed to the austempering of original martensitic structure of AISI D2 steel. The generated grinding heat is at the origin of the tensile residual stress distribution as shown in Fig. 3. The higher near surface tensile residual stress is associated to the $\mathrm{Al}_{2} \mathrm{O}_{3}$ grinding wheel (95 A $46 \mathrm{H} \mathrm{V} \mathrm{S}$ ) characterized by the lower thermal conductivity.

The loading at an imposed stress level close to the fatigue limit, deforms plastically the softened layers (depth lower than $20 \mu \mathrm{m}$ ) of notch root zone and consequently induces a significant residual stress relaxation in this region (Fig. 3). Indeed, the relaxation of $88 \%$ of initial value of near surface residual stress is the result of plastic misfit change $(35 \%)$ under cyclic loading as shown by comparing microhardness profiles before and after loading. However, the subsurface hardness is slightly modified and the residual stress relaxation was expected as a consequence of stress rebalancing resulting from the near surface relaxation.

The effect of stabilized residual stress on the fatigue resistance is taken into account by Dang Van multi axial fatigue criteria as a hydrostatic mean stress. The material parameters $\alpha_{D}=1.48$ and $\beta_{D}$ $=201 \mathrm{MPa}$ corresponding to Dang Van criteria were identified by two experimental fatigue limits at stress ratio $R_{0.1}$ and $R_{0.5}$ (Fig. 4). This criterion predicts suitably the experimental fatigue results since the criterion line for $2.10^{6}$ cycles separates fractured state (above) from unfractured ones (below). Moreover, the detrimental effect of tensile residual stress is evidenced by comparing the fatigue resistance of ground surface by sol gel and $\mathrm{Al}_{2} \mathrm{O}_{3}$ wheels. It has been established that the control of grinding residual stress leads to an improvement rate of AISI D2 fatigue limit at $2.10^{6}$ cycles equal to $100 \%$. Indeed, experimental fatigue limit at $2.10^{6}$ cycles varies from $143 \mathrm{MPa}$ to $296 \mathrm{MPa}$ when grinding is conducted using a sol gel wheel instead of AL2O3 wheel. This improvement rate is mainly attributed to the residual stress effect as predicted by Dang Van criteria $\left(\left(\tau_{h a, S G}-\tau_{h a, A_{2} O_{3}}\right) / \tau_{h a, A l_{2} O_{3}}=80 \%\right)$ shown in Fig. 4 .

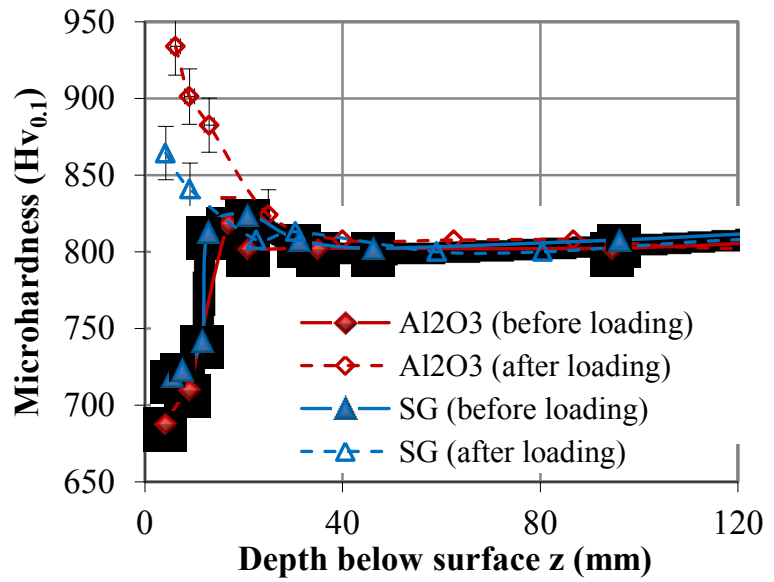

Fig. 2 Work hardening before and after cyclic loading at imposed stress level close to the fatigue limit 


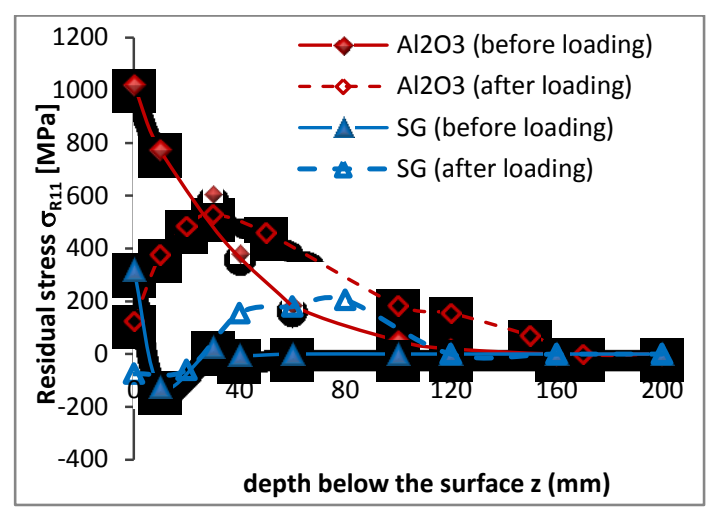

(a)

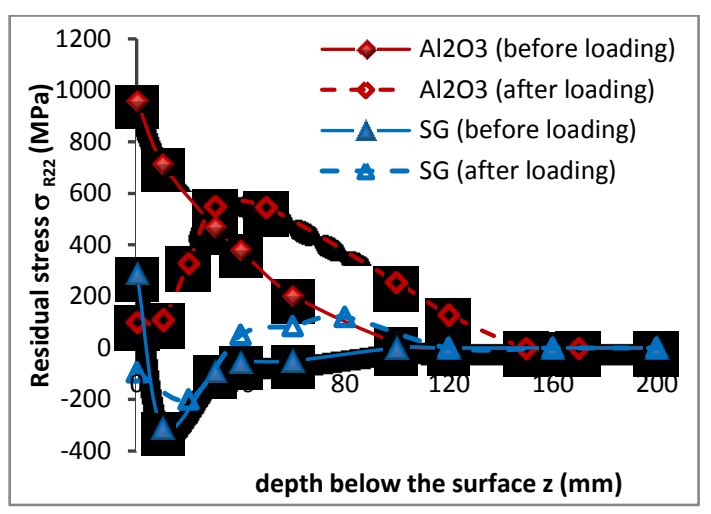

(b)

Fig. 3 Residual stresses before and after cyclic loading at imposed stress level close to the fatigue limit

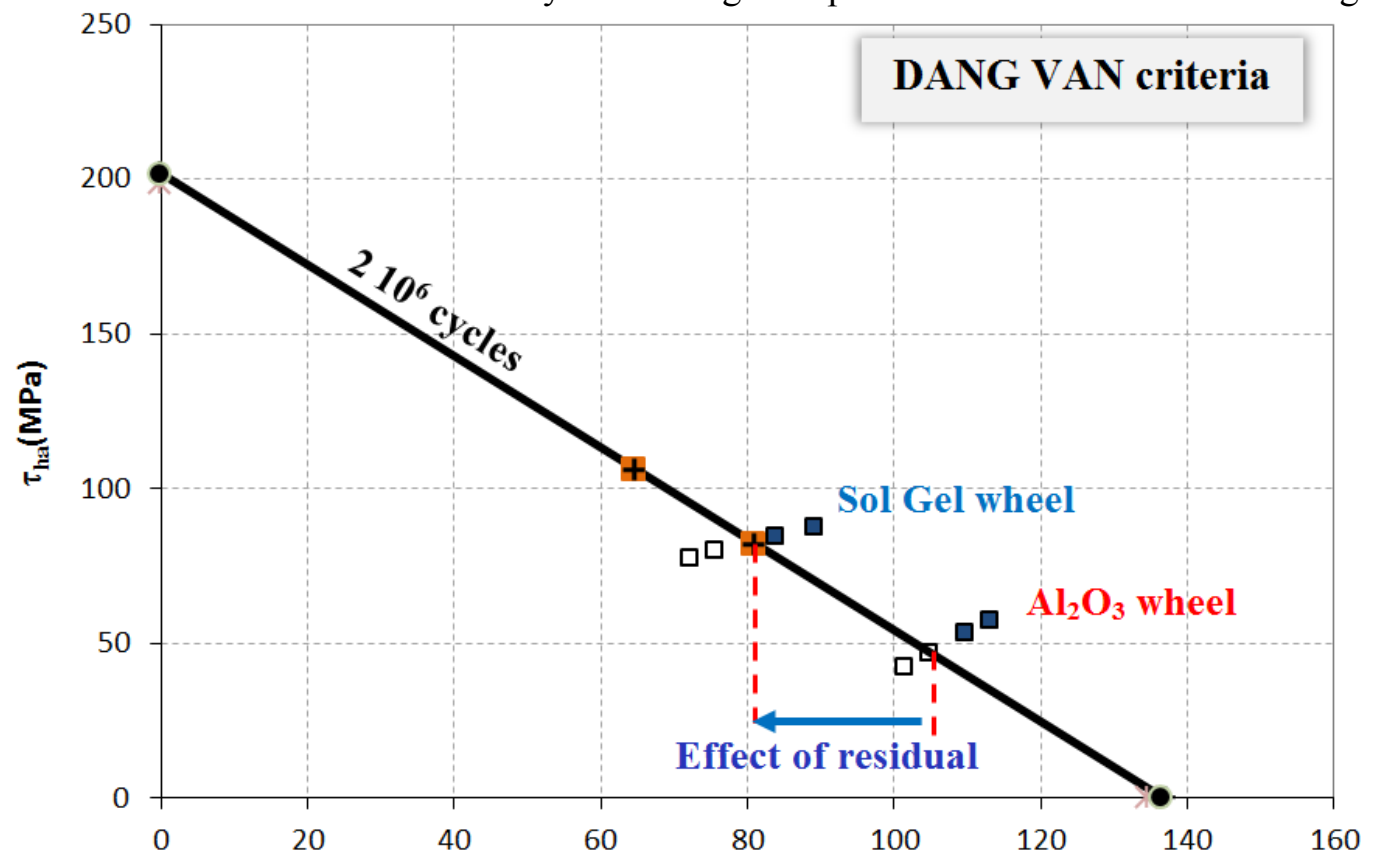

Fig. 4 Effect of grinding residual stress on the fatigue strength improvement of AISI D2 steel

\section{Cyclic stability of residual stress in AA 5083-H111 hammered surface and their consequences on fatigue strength}

A numerical procedure has been developed, using ABAQUS software, to predict residual stress redistribution and work hardening modification under cyclic loading. The organization chart of the proposed procedure, given in Fig. 5, requires initial work hardening and residual stress profiles, cyclic material behaviour law, and applied cyclic loading conditions. At least two experimental stabilized residual stress profiles are needed to validate the numerical procedure. Using multi-axial criteria, accounting for residual stress and work hardening, the developed procedure predicts suitably the fatigue life. The application of this procedure on the as machined and hammered AA 5083-H111, leads to the following results:

- The stabilized residual stress was satisfactory predicted by taking into account the initial work hardening with respect to the experimental results (Fig.6).

- The relaxation of residual stress is strongly dependent on the applied stress and the stress ratio (Fig.6).

- The cyclic loading of machined notched specimen induces an additional compressive residual stress. The residual stress redistribution is achieved during the first cycle at low applied stress (Fig.7 (a)).

- The cyclic loading of hammered notched specimen induces an additional compressive residual stress. The most fraction of residual stress redistribution is achieved during the first cycles at high applied stress (Fig.7 (b)). 
- The beneficial effect of surface treatment by wire brush hammering on the residual stress stability is proved.

- The experimental fatigue data shows an improvement fatigue rate close to $20 \%$ by wire brush hammering. The Sines multi-axial fatigue criteria $(\alpha=0.26, \beta=65 \mathrm{MPa})$ attributes this enhancement to the effect of stabilized compressive residual stress (Fig. 8).

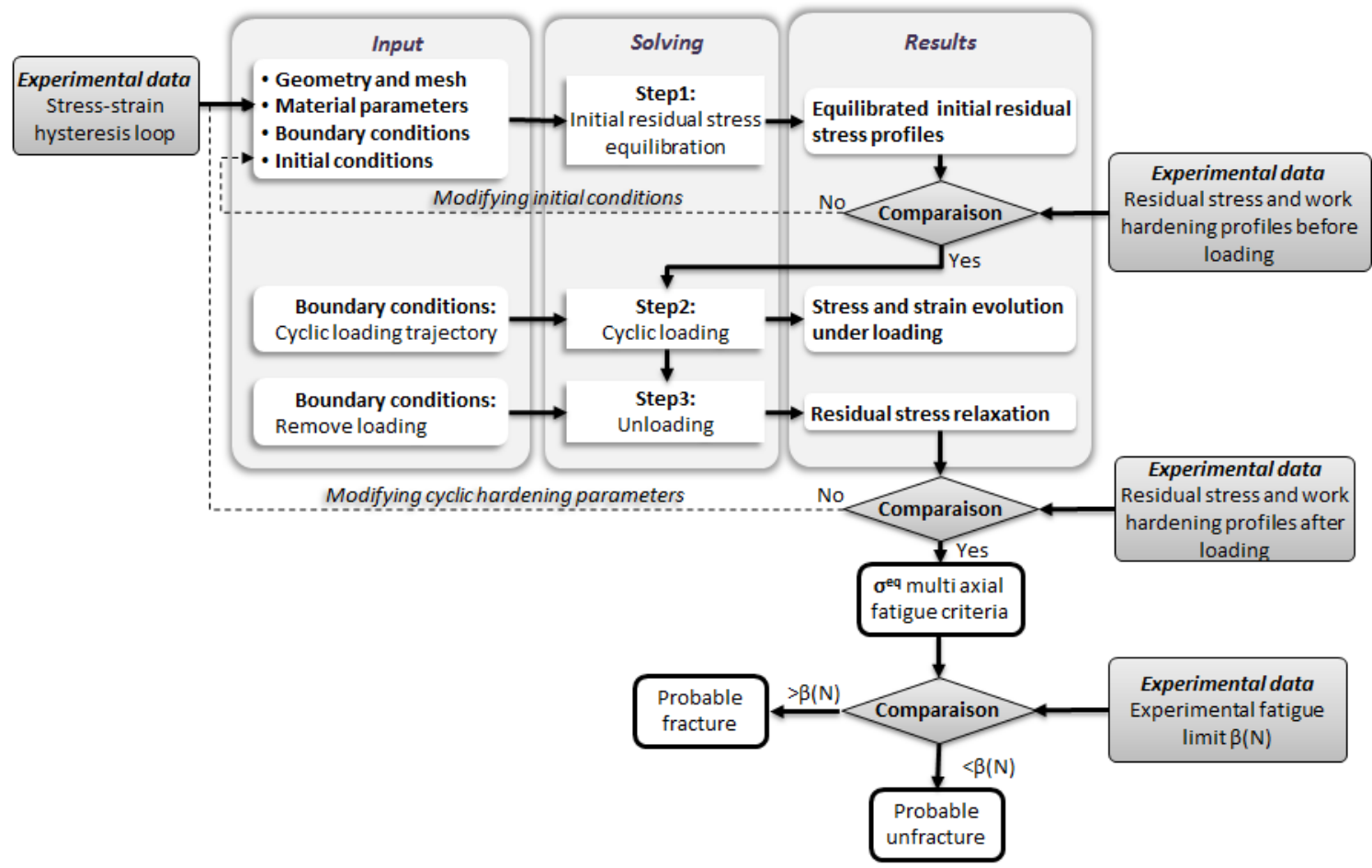

Fig. 5 Numerical procedure for residual stress relaxation and fatigue life time prediction

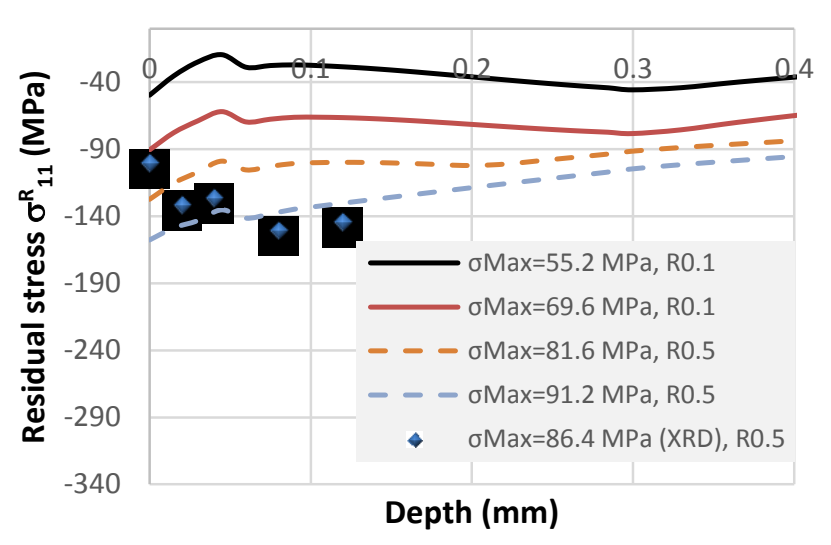

(a)

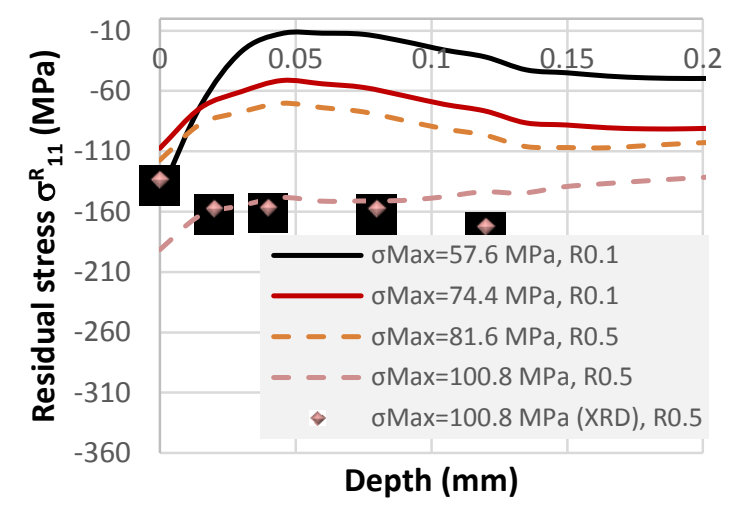

(b)

Fig. 6 AA 5083-H111 stabilized residual stress (in loading direction) under various loading paths, a: machined state, $b$ : wire brush hammered state 


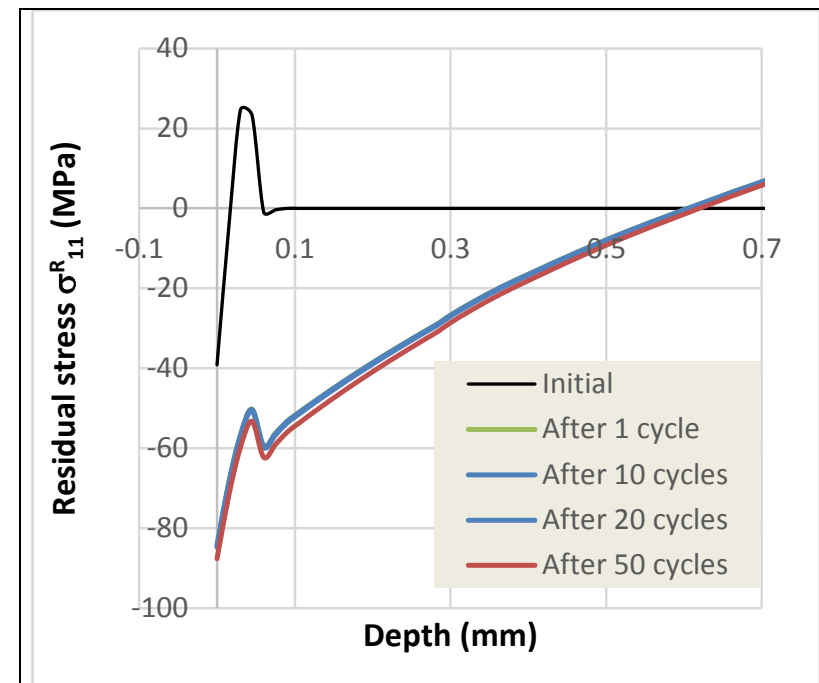

(a)

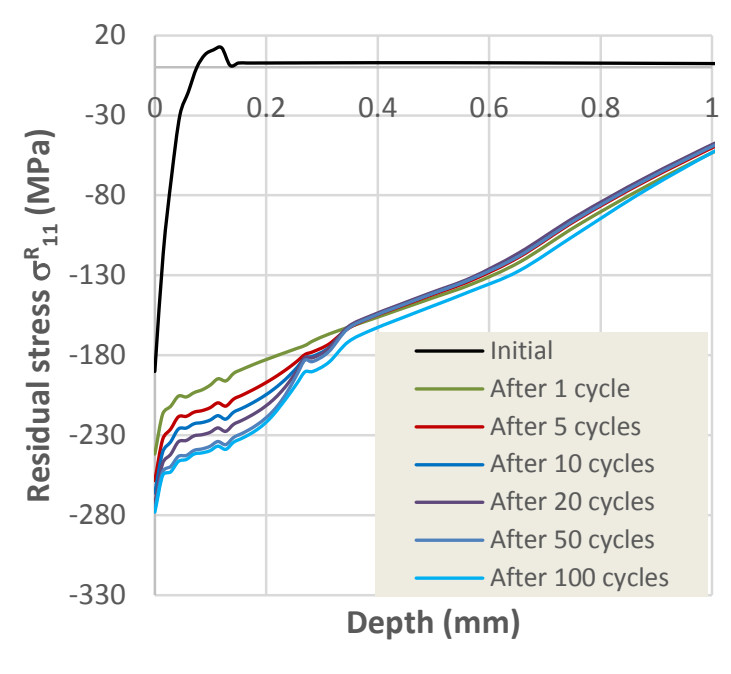

(b)

Fig. 7 AA 5083-H111 residual stress redistribution, (a): machined state load at low stress $(\sigma \mathrm{Max}=96 \mathrm{MPa}$, $\left.\mathrm{R}_{0.1}\right)$, (b): hammered state loaded at high stress ( $\left.\sigma \mathrm{Max}=144 \mathrm{MPa}, \mathrm{R}_{0.1}\right)$

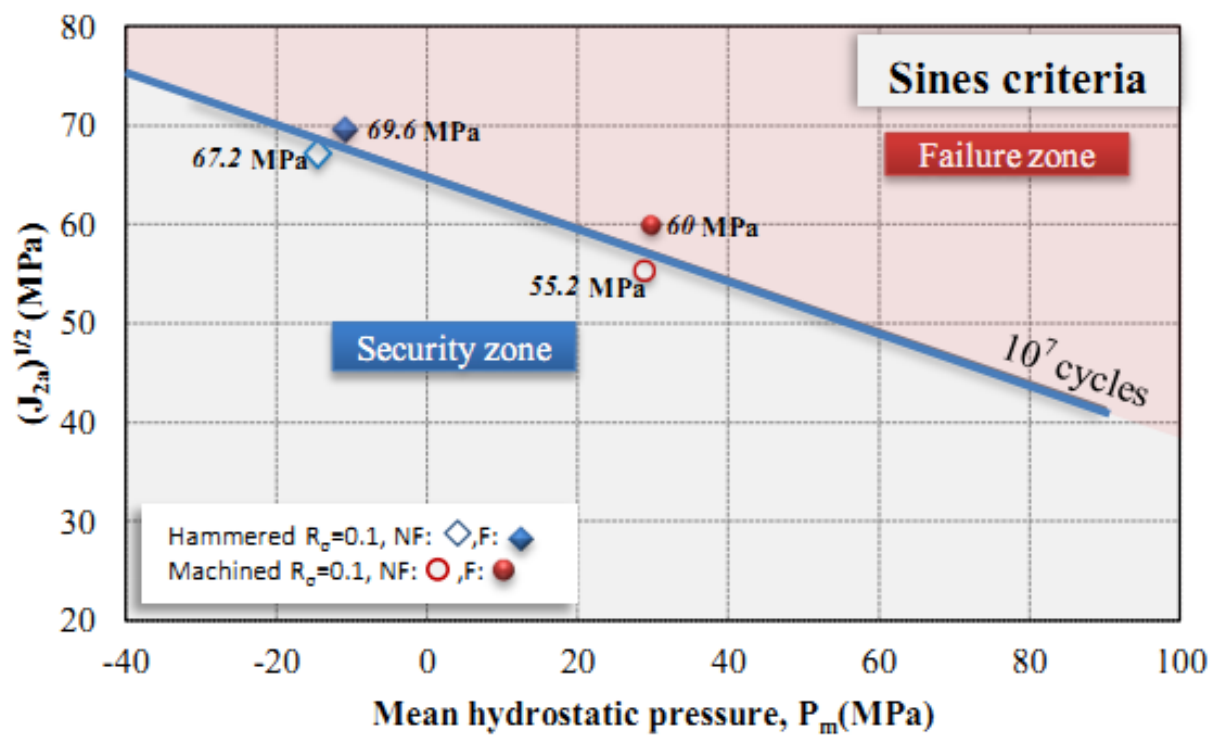

Fig. 8 Effect of surface mode preparation on the AA 5083-H111 fatigue strength improvement predicted by Sines criteria accounting for work hardening and residual stress

\section{Conclusion}

The interdependence between work hardening modification and residual stress redistribution under cyclic loading is demonstrated by the experimental (AISI D2) and numerical (AA 5083-H111) approaches. Higher is the near surface work hardening more stable is the initial residual stress distribution. Accounting for these surface characteristics by multi-axial fatigue criteria, the fatigue life of machined and treated parts has been satisfactory predicted and the beneficial effect of compressive residual stress is assessed.

\section{References}

[1] Fathallah R, Laamouri A, Sidhom H, Braham C. High cycle fatigue behavior prediction of shotpeened parts. International Journal of Fatigue. 2004;26:1053-67.

[2] Fathallah R, Sidhom H, Braham C, Castex L. Effect of surface properties on high cycle fatigue behaviour of shot peened ductile steel. Materials Science and Technology. 2003;19:1050-6.

[3] Sidhom N, Laamouri A, Fathallah R, Braham C, Lieurade HP. Fatigue strength improvement of 5083 H11 Al-alloy T-welded joints by shot peening: experimental characterization and predictive approach. International Journal of Fatigue. 2005;27:729-45. 
[4] Sidhom N, Braham C, Lieurade HP. Fatigue life evaluation of shot peened al-alloys 5083 H11 T-welded joints by experimental and numerical approaches. Welding in the World. 2007;51:50-7.

[5] Terres MA, Sidhom H. Fatigue life evaluation of $42 \mathrm{CrMo} 4$ nitrided steel by local approach: Equivalent strain-life-time. Materials \& Design. 2012;33:444-50.

[6] Makhlouf K, Sidhom N, Khlifi A, Sidhom H, Braham C. Low cycle fatigue life improvement of AISI 304 by initial and intermittent wire brush hammering. Materials \& Design. 2013;52:1088-98.

[7] Ghanem F, Braham C, Sidhom H. Influence of steel type on electrical discharge machined surface integrity. Journal of Materials Processing Technology. 2003;142:163-73.

[8] Ghanem F, Fredj NB, Sidhom H, Braham C. Effects of finishing processes on the fatigue life improvements of electro-machined surfaces of tool steel. The International Journal of Advanced Manufacturing Technology. 2011;52:583-95.

[9] Benedetti M, Bortolamedi T, Fontanari V, Frendo F. Bending fatigue behaviour of differently shot peened Al 6082 T5 alloy. International Journal of Fatigue. 2004;26:889-97.

[10] Benedetti M, Fontanari V, Monelli BD. Plain fatigue resistance of shot peened high strength aluminium alloys: Effect of loading ratio. Procedia Engineering. 2010;2:397-406.

[11] Benedetti M, Fontanari V, Scardi P, Ricardo CLA, Bandini M. Reverse bending fatigue of shot peened 7075-T651 aluminium alloy: The role of residual stress relaxation. International Journal of Fatigue. 2009;31:1225-36.

[12] Ben Fredj N, Ben Nasr M, Ben Rhouma A, Sidhom H, Braham C. Fatigue life improvements of the AISI 304 stainless steel ground surfaces by wire brushing. Journal of materials engineering and performance. 2004;13:564-74.

[13] Laamouri A, Sidhom H, Braham C. Evaluation of residual stress relaxation and its effect on fatigue strength of AISI 316L stainless steel ground surfaces: Experimental and numerical approaches. International Journal of Fatigue. 2013;48 109-21.

[14] Dalaei K, Karlsson B, Svensson LE. Stability of shot peening induced residual stresses and their influence on fatigue lifetime. Materials Science and Engineering: A. 2011;528:1008-15.

[15] Sidhom N, Sidhom H, Braham C, Lédion J. Effects of brushing and shot-peening residual stresses on the fatigue resistance of machined metal surfaces: experimental and predicting approaches. Materials Science Forum: Trans Tech Publ; 2011. p. 290-5.

[16] Lemaitre J, Chaboche J. Mécanique des matériaux solides. Dunod, Paris. 2001. 